\title{
Carbon Emission and the Fixed Asset Investment of Financial Industry: Evidence from Chinese Provincial Data
}

\author{
Yang Cai ${ }^{1}$, Ke Gao ${ }^{2,3}$, Yongsheng Wang ${ }^{1}$, Xiaojing Hao ${ }^{4}$, \\ ${ }^{1}$ School of Management Science and Engineering, Central University of Finance and Economics, Beijing, P. R. China \\ ${ }^{2}$ PBC School of Finance, Tsinghua University, Beijing, P. R. China \\ ${ }^{3}$ Development Research Center of Shandong Provincial People's Government, Jinan, P. R. China \\ ${ }^{4}$ School of Public Finance and Tax, Central University of Finance and Economics, Beijing, P. R. China
}

Email address:

Elaine_working@163.com (Xiaojing Hao)

*Corresponding author

\section{To cite this article:}

Yang Cai, Ke Gao, Yongsheng Wang, Xiaojing Hao. Carbon Emission and the Fixed Asset Investment of Financial Industry: Evidence from Chinese Provincial Data. International Journal of Environmental Monitoring and Analysis. Vol. 6, No. 5, 2018, pp. 131-143.

doi: 10.11648/j.ijema.20180605.12

Received: November 13, 2018; Accepted: December 3, 2018; Published: December 11, 2018

\begin{abstract}
This study examines the effect of the structure of investment in the fixed asset on provincial carbon emission in China, and investigates the channels behind this effect. Using a panel of the provincial data from 2003 to 2016, we identify the significant negative relationship between fixed asset investment of finance and local carbon emission in China. We further apply spatial econometric empirical strategy to explore the spatial effect of fixed asset investment of finance on the provincial carbon emission. Using the adjacent matrix, distance matrix and gravity matrix, it is found that the effect is similar when the spatial correlation influence is considered and to some extent, local investment in the fixed asset of financial industry may give rise to the increase of carbon emission of the surrounding provinces. Moreover, after considering the regional heterogeneity, partial evidence indicates that this negative effect only exists in the sample of eastern part provinces. Furthermore, this study also finds two channels that fixed asset investment of financial industry affects local carbon emission: financial market and the related technological innovations. Through developing financial market and improving technical innovation, the fixed asset investment of financial industry reduces the local carbon emission level. In addition, a relevant case is constructed and we found that financial fixed asset investment promotes technology transfer as well. Using relevant variables, proxies and different estimation models, the results are found robust. This paper contributes to provide a new insight into the influence of structure of fixed asset investment on carbon emission.
\end{abstract}

Keywords: Carbon Emission, Finance, Fixed Asset Investment

\section{Introduction}

China now has become the largest carbon emitter in the world, accounting for $28 \%$ of the total and expected to rise by $3.5 \%$ in 2017 (GCP, 2017). As a major developing country, China is still in the process of rapid industrialization and urbanization, and with the continuous growth of economy, China inevitably experiences a significant rise in energy consumption and carbon emissions in recent decades $[1,2]$. Facing the great pressure from reducing energy consumption and $\mathrm{CO}_{2}$ emissions, China needs to find new development paths, for example, low-carbon development [3]. Recently, new development philosophies haven been frequently mentioned in Chinese official discourse, as China aims to create a green and low-carbon economy by spurring the development of energy-saving and environmental protection industries. In addition, under the context of addressing global climate change, Chinese government has made an announcement in the Paris Agreement, promising to lower $60 \%-65 \%$ carbon emissions by 2030 , compared with the level of 2005. Therefore, how to find an effective way to reduce carbon emissions is a serious challenge for China.

There are numerous factors involved in the reduction of carbon emissions, and previous studies were mainly focused 
on the aspects of energy consumption and low carbonization at different levels, ranging from individual practice $[4,5]$, household mitigation actions [6-8]. As the main component of energy consumption, industrial sector is extremely energy intensive and accounts for $40 \%$ of global energy use [9]. More specifically, the sub-sector of electricity characterized by its largest emission of all sectors and fast growth in emission, has naturally become the study focus in this field [10, 11], and other sub-sectors such as cement, iron and steel industries also contribute large amount of carbon emission and this problem has been discussed frequently [12-15]. Meanwhile, based on the regional or national level, many studies have explored the causal relationship between carbon emissions, energy consumption and economic growth $[1,16]$, as well as the income and trade [17], demographic change [18], urbanization [19], etc. In fact, the carbon emissions in China do not necessarily depend on its energy consumption alone. The structure of industrial investment may be another source that counts.

Since the financial crisis in 2008, the Chinese government has made large-scale investments. Although most of the investment was used to support the livelihood security and infrastructure industries, it also indirectly stimulated the development of relevant industries and caused a large amount of carbon emissions. Few studies are focused on the carbon emissions caused by investments activities, as more attention is paid to the relationship between foreign direct investment (FDI) and carbon emissions [20, 21]. Compared with fixed asset investment, the carbon emissions caused by FDI are relatively small. At present, China's investment in fixed assets is about two-thirds of the national GDP. Therefore, the structure of fixed assets investment and its dynamic changes will influence the energy use efficiency and an essential factor requiring consideration in order to achieve the low-carbon goals.

From another perspective, the effects of financial development on carbon emissions have been a hot topic for many years. Many different viewpoints have been proposed on whether financial development reduces carbon emissions or not [22]. Some studies show that financial development increases carbon emissions, and similar views can be found in the work by Frankel \& Romer [23] and Dasgupta et al. [24]. In the latest time, more researchers tend to acknowledge the fact that financial development has led to a decrease in environmental pollution [25-27]. Shahbaz et al. [26, 27] argued that financial development and trade openness will reduce $\mathrm{CO}_{2}$ emissions. Similarly, Boutabba [28] also found that financial development has a long-run positive impact on per capita $\mathrm{CO}_{2}$ emissions and mitigates environmental degradation. In short, the role of financial development in carbon emissions tends to be continuously growing for several reasons, including stock market development, FDI attraction, financial intermediation prosperity and firm performance spur, etc. [2, 25]. Comparatively, the influence of financial fixed assets investment on carbon emissions and energy consumption is rarely studied. As the carbon emissions in China are largely driven by fixed assets investment, it is necessary to analysis the impact of fixed asset investment in financial development on carbon emissions.

In 2016, the financial fixed assets investment of China has reached CNY 131 billion1 and has profoundly affected the development of financial market. Just as mentioned above, financial development may decrease/increase the carbon emissions through many ways. Under this circumstance, the causal relationship between the structure of fixed assets investment, especially the financial sector, and carbon emissions still remains unclear, and previous empirical studies are not sufficient. In fact, this kind of work is of great importance for China to scientifically design the measures to reduce carbon emissions and reasonably evaluate the difficulty of achieving the goal of carbon emissions reduction by 2030 . If there is a significantly positive relationship between financial fixed assets investment and carbon emissions, then the further development of China's financial sector may increase carbon emissions in a way that was not considered before. This will make it more difficult for China to meet its goal of preplanned carbon emissions reduction.

In response to this question, this paper starts from the point of fixed assets investment of finance and try establishing its causal relationship with carbon emissions. Like the results of some recent studies, we also believe that financial market development can reduce carbon emission. But the essential difference of our study from the previous studies lies in that financial fixed assets investment and its structural changes may first promote the financial market development, and vice versa. On the other side, the infrastructure construction in financial industry may form a good expectation for financial market development, so as to improve the local financial industry. Therefore, financial market development stemming from financial fixed asset investment will further accelerate the technical innovation, and eventually reduce the carbon emission through increasing energy use efficiency.

Based on the theory aforementioned, the rest of the paper is structured as follows. In section 2, the models specification and relevant data are described. Section 3 shows the empirical results and discusses the potential channels of this effect, and the robustness check is exploited as well. In the final section, the results are summarized and some conclusions are made.

\section{Model Specification and Data}

\subsection{Model Specification}

To test the story we have formed, first we construct our empirical strategy basing on the Stochastic Impacts by Regression on Population Affluence and Technology (STIRPAT) model established by Dietz and Rosa [29], and this paper incorporates the model with the structure financial fixed asset investment variable. According to the standard STIRPAT model:

$$
I=a P^{\theta_{1}} A^{\theta_{2}} T^{\theta_{3}} e
$$

Where the $I$ is the carbon emission of a specific Chinese province; $a$ is constant term; $P$ tells the population scale; $A$ 
represents the per capita affluence and is usually proxied by per capita GDP; $T$ displays the technology level of the sample province and $e$ is the error term. As suggested by the original analysis, $\theta_{1}>0, \theta_{2}>0$ and $\theta_{3}<0$, indicating that the increase of population scale and per capita affluence will lead to more the carbon emission; by contrast, higher technology level of energy will lead to the reduction the carbon emission level.

The story abovementioned shows that amore developed financial market contributes to improve the technical innovation [30], thus it is reasonable to suggest that the technology level is a function of financial development. Further, the financial fixed asset investment is an important way to boost the financial development, thus the technology level of energy utilization also can be seen as an increasing function of the structure of financial fixed asset investment (fin):

$$
T=T(\text { fin })=T_{0} \text { fin }^{\lambda}, \lambda>0
$$

where $T_{0}$ is constant term, representing the other factors that affect the technology of energy use; fin represents the variable of the structure ofthe financial fixed asset investment; $\lambda$ is the elasticity of the technology level by financial fixed asset investment. Combing the equation (1) and (2), we can have:

$$
I=a P^{\theta_{1}} A^{\theta_{2}} T_{0}^{\theta_{3}} \text { fin }^{\gamma} e
$$

where $\gamma=\lambda \times \theta_{3}$, which illustrate the elasticity of carbon emission by the structure of financial fixed asset investment and reflects the effect of it on the regional carbon emission. With the logarithm, equation (3) changes to following form:

$$
\ln I_{i t}=\alpha+\theta_{1} \ln P_{i t}+\theta_{2} \ln A_{i t}+\gamma \ln f i n_{i t}+\varepsilon_{i t}
$$

where $\alpha=\ln a+\theta_{3} \ln T_{0}$. In equation (4), the effect of investment in fixed asset of finance is lagged since it is rational to consider that the financial fixed asset investment cannot play a role immediately. Additionally, other relevant variables that may affect carbon emission are taken into consideration. For example, the industry structure [31], foreign direct investment [32] and human capital [33]. These variables will be introduced into subsequent analysis as well.

To estimate equation (4), we first exploit the fixed effect identification strategy to start the analysis. However, since carbon emission is as an external factor in economic development, it may diffuse with the climate change between regions and also change with the industrial transfer, the spatial correlation effect of the carbon emission is supposed to be significant to some extent. Moreover, interregional competition may indirectly cause the carbon emission correlation as well. The pressure of increasing competition and political promotion could result in the local governments' reduction of environmental standards and energy use intensity standards so that this region can attract more business investment. Similarly, other regions may also induce the same activities and this strategic interaction between local governments leads to the non-completed implementation of central government's environmental regulation policy [34].
This interaction provides more evidence of the existing spatial correlation of carbon emission in our estimation.

In addition to the spatial correlation of carbon emission, the variables which are introduced in our model may also have spatial correlation. For example, China is always divided into three regions: eastern area, middle area and western area. These areas have their own similar characteristics since in one specific area, provinces have similar geographic features and factors such as education and capital will flow between regions more easily, so it is rational to argue that the spillover effect exists. Therefore, it is necessary to utilize the spatial identification strategy into the econometric analysis. The general spatial econometric model is as follow:

$$
\begin{aligned}
& \ln I_{i t}=\alpha+\tau \ln I_{i t-1}+\rho W \ln I_{i t}+X_{\mathrm{it}} \beta+\theta W X_{\mathrm{it}}+\mu_{i}+v_{t}+\varepsilon_{i t} \\
& \varepsilon_{i t}=\lambda W \varepsilon_{i t}+\mu_{i t}
\end{aligned}
$$

where the $X$ is the vector of independent variables, containing the investment structure in fixed asset of finance, population scale, per capita GDP, industry structure, human capital and foreign direct investment. $W \ln I_{i t}$ represents the endogenous interaction effects of dependent variable, which is the carbon emission in our estimation; $W X_{i t}$ measures the exogenous interaction effect between the independent variables and other control variables; $W \varepsilon_{i t}$ is the interaction effect of error terms of different locations. $\rho, \theta, \lambda$ is the regression coefficients with respect to these three interaction effects. Equation (5) shows all the effects and generally, the endogenous and exogenous interaction effects are the main effects in spatial spillover effects [35]. In the process of identifying the spatial econometric model, rules are as follow: if $\lambda=0$, the model is simplified into Spatial Durbin Model (SDM). Then if $\rho \neq 0, \theta=0$, SDM model can further be simplified into Spatial Auto regression Model (SAR), which measures the endogenous spatial interaction's spillover effect; if $\rho=0, \theta \neq 0$, equation (5) is the spatial lag explanatory model (SLX), which measures the exogenous interaction effect of explanatory and other control variables; if $\rho \neq 0, \theta \neq 0$, then the equation (5) is standard SDM model and contains both endogenous and exogenous interaction effects. When $\lambda \neq 0$, equation (5) is spatial error model (SEM), which tests the spatial dependence of the error term. Since this paper is to examine the spillover effect of the financial fixed asset investment on carbon emission, we mainly focus on the SDM model.

\subsection{Variable and Data}

Due to lack of the data from Tibet, we mainly use the sample contains 30 provinces, autonomous regions and municipal cities of China. The statistics of fixed assets in sub sectors starts in 2003, therefore we analysis the data from 2003 to 2016. Data are derived from China Energy Statistics Yearbook, Statistic Year Book for Regional Fixed Assets Investment, Statistical Yearbook of China and China Statistical Yearbook for Regional Economy. Main variables and the measures are as follows: 
(1) The dependent variable is the regional carbon emission. Reginal carbon emission is mainly produced from the energy consumption. Given the availability of data and due to the statistical indicators in energy consumption according to National Bureau of Statistics of China, we select the main eight kinds of energy sources, including coal, coke, crude oil, gasoline, kerosene, diesel oil, fuel oil, natural gas. To compute the carbon emission, the equation is as follow:

$$
C E_{i t}=\sum F_{i j t} \times C V_{j} \times C C F_{j} \times C O F_{j} \times \frac{44}{12}
$$

where $C E_{i t}$ is the total amount of carbon emissions from energy consumption province $i$ at year $t$ (10 thousand tons); $F_{i j t}$ represents terminal fossil energy consumption in province $i$ of specific fossil energy jin tyear (10 thousand tons or 100 million cubic meters), and the data is from China Energy Statistics Yearbook; $C V_{j}$ represents the average low calorific value $\left(\mathrm{KJ} / \mathrm{kg}\right.$ or $\left.\mathrm{KJ} / \mathrm{m}^{3}\right)$ of the specific fossil energy $j$. The data comes from China Energy Statistics Yearbook. $C C F_{j}$ is the content of carbon element of the specific fuel $j\left(\mathrm{Kg} / 10^{6} \mathrm{KJ}\right)$ and we obtain the data from the IPC (2006) National Greenhous Gas Inventories; $C O F_{j}$ indicates the carbon oxidation rates and the data is from China Provincial Greenhouse Gas Inventory Guidelines; 44 and 12 represent the atomic weight of $\mathrm{CO}_{2}$ and Carbon separately.

(2) The explanatory variables in our research is the structure of financial fixed asset investment. Considering that this variable should measure the structure change of the investment in fixed asset, we first define the variable, fin $_{i t}$, in the measurement of the proportion of investment in fixed asset of finance by total fixed asset investment of province $i$ in the year of $t$. This measurement represents the absolute proportion of the fixed asset investment, and also, can be regarded as the proxy. In the subsequent analysis, following [36], we also apply the relative proportion of the financial fixed asset investment by measuring the relative ratio of i) fixed assets investment of finance divided by transportation fixed asset investment, ii) fixed assets investment of finance divided by transportation investment plus public infrastructure investment and real estate. The coefficient of these variable sare expected to be negative according to our abovementioned story.

(3) Control variables are introduced following STIRPAT model and related literatures. According to STIRPAT model, we still introduce the control variables as follows: population $\left(\right.$ lnpopulation $\left._{i t}\right)$, per capital GDP $\left(\operatorname{lnag} d p_{i t}\right)$, human capital $\left(\operatorname{lne} d u_{i t}\right)$, foreign direct investment $\left(f d i_{i t}\right)$ and industry structure $\left(\right.$ industry $_{i t}$ ). The Inpopulation $_{i t}$ variable is the logarithm of the population size in province $i$ in year $t$, and the data comes from Statistical Yearbook of China; per capital GDP measures as the logarithm of per capita GDP in province $i$ in year $t$ and data is from the China Statistical Yearbook for Regional Economy; we apply the logarithm of total number of staff in college and universitiesas the proxy variable that measures the human capital of the province $i$ in the year $t$, which is represented bylned $u_{i t}$. This data is obtained from Statistical Yearbook of China. Moreover, since a number of literatures emphasize the impact of foreign direct investment, we use the foreign direct investment adjusted by GDP of province $i$ in year $\mathrm{t}$, which is $f d i_{i t}$, to control the effect of foreign direct investment. Also, industry $_{i t}$, the variable measures the effect industry structure is introduced. We exploit the proportion of secondary industry as the proxy of industry structure and the data of abovementioned two variable is both from China Statistical Yearbook for Regional Economy. All the variables which are relevant to GDP have been adjusted by inflation, which taking the 2003 as the base year since our data starts from 2003. The detailed information of the main variables is shown in Table 1.

Table 1. Descriptive Summary Statistics1.

\begin{tabular}{|c|c|c|c|c|c|c|}
\hline Variable & Description & $\begin{array}{l}\text { Number of } \\
\text { observation }\end{array}$ & Mean & $\begin{array}{l}\text { Standard } \\
\text { deviation }\end{array}$ & Median & Data Source \\
\hline $\operatorname{lnce}_{\text {it }}$ & $\begin{array}{l}\text { Logarithm of carbon emission, } \\
10000 \text { ton }\end{array}$ & 420 & 10.133 & 0.785 & 10.153 & $\begin{array}{l}\text { China Energy Statistics Yearbook; } 2006 \text { IPCC } \\
\text { Guidelines for National Greenhouse Gas } \\
\text { Inventories }\end{array}$ \\
\hline $\mathrm{fin}_{\text {it }}$ & $\begin{array}{l}\text { The proportion of financial } \\
\text { investment in fix asset, } \%\end{array}$ & 420 & 0.197 & 0.148 & 0.165 & $\begin{array}{l}\text { Statistical Yearbook of China; Statistic Year } \\
\text { Book for Regional Fixed Assets Investment }\end{array}$ \\
\hline lnpopulation $_{\text {it }}$ & $\begin{array}{l}\text { Logarithm of population size in } \\
\text { each province, } 10000 \text { people }\end{array}$ & 420 & 17.374 & 0.752 & 17.458 & Statistical Yearbook of China \\
\hline $\operatorname{lnagdp}{ }_{\text {it }}$ & $\begin{array}{l}\text { Logarithm of per capita in each } \\
\text { province }\end{array}$ & 420 & 10.159 & 0.771 & 10.263 & $\begin{array}{l}\text { China Statistical Yearbook for Regional } \\
\text { Economy }\end{array}$ \\
\hline $\operatorname{lnedu}_{\text {it }}$ & $\begin{array}{l}\text { Logarithm of total number of } \\
\text { staff in college and universities, } 1 \\
\text { person }\end{array}$ & 420 & 10.900 & 0.794 & 11.091 & Statistical Yearbook of China \\
\hline $\mathrm{fdi}_{\text {it }}$ & $\begin{array}{l}\text { The proportion of FDI, adjusted } \\
\text { by GDP in each province }\end{array}$ & 420 & 0.407 & 0.518 & 0.209 & $\begin{array}{l}\text { China Statistical Yearbook for Regional } \\
\text { Economy }\end{array}$ \\
\hline industry $_{\mathrm{it}}$ & $\begin{array}{l}\text { The proportion of secondary } \\
\text { production in GDP }\end{array}$ & 420 & 0.419 & 0.084 & 0.402 & $\begin{array}{l}\text { China Statistical Yearbook for Regional } \\
\text { Economy }\end{array}$ \\
\hline
\end{tabular}




\section{Empirical Results}

\subsection{Baseline Regression}

Next, we first estimate the variants of equation (4) to see with general OLS estimation, what the casual effect of investment in fixed asset of finance is. We exclude the potential spatial spillover effect of the variables in this part and the results are presented in Table 2. In column (1) and (2), we apply the fixed effect identification strategy of OLS. The regression in column (1) excludes the control variables and in column (2) control variables are introduced. To solve the problem of endogeneity, in column (3) to column (4), we further apply the instrumental variable method. Following a number of literatures, we use the $f i n_{i t}$ that lagged 1 to 2 orders as the instrument variables set of the explanatory variable, and control variables are included. The coefficients on $\mathrm{fin}_{i t}$ are all statistically negative. The first stage regression result, which shows in column (3), indicating that these two variables are significantly related to $\mathrm{fin}_{i t}$. In column (4), Kleibergen-Paap LM statistic and Cragg-Donald Wald F statistic are both statistically significant at $1 \%$ and $10 \%$ respectively, indicating that the instrument variables, which are measured by the lagged 1 to 2 orders of $f i n_{i t}$, have passed the under identification and weak instrument test. Furthermore, the Sargan-Hansen $\mathbf{J}$ statistic illustrates this instrument variable set passes the over identification test. Applying the instrument variable method, the results are still showing a significant negative effect of the structure of financial fixed asset investment on regional carbon emission and without IV method, we may underestimate the effect of $f i n_{i t}$. Overall, these results are consistent with our previous expectation.

Table 2. Baseline Regression Results.

\begin{tabular}{|c|c|c|c|c|}
\hline & (1) OLS & (2) OLS & (3) IV-FIRST & (4) IV-2SLS \\
\hline $\mathrm{fin}_{\mathrm{it}}$ & $-0.408 * * *(0.077)$ & $-0.345 * * *(0.081)$ & & $-0.823 * * *(0.205)$ \\
\hline fin $_{\text {it-1 }}$ & & & $0.306 * * *(0.082)$ & \\
\hline fin $_{\text {it-2 }}$ & & & $0.200 * * *(0.074)$ & \\
\hline Region Fixed Effect & YES & YES & YES & YES \\
\hline Year Fixed Effect & YES & YES & YES & YES \\
\hline Kleibergen-Paap LM (p-value) & & & & $35.844(0.000)$ \\
\hline Stock-Yogo- $10 \%$ & & & & 19.93 \\
\hline Sargan-Hansen J (p-value) & & & & $0.070(0.7917)$ \\
\hline No. of Observation & 390 & 390 & 360 & 360 \\
\hline
\end{tabular}

Notes: ${ }^{* * * * * *}$ are significant level at $1 \%, 5 \%$ and $10 \%$. Robust standard deviation is in parentheses.

\subsection{Spatial Correlation Analysis}

Considering the spatial correlation of carbon emission helps to form a more effective estimation of the effect of the key explanatory variable and to study the spatial mechanism of carbon emission between different regions. In spatial econometric estimation, the construction of the spatial weight matrix is key to analyze the spatial correlation. Following traditional spatial econometric literatures, this paper first apply the adjacent weight matrix. In adjacent matrix, the individuals that have the same boundary, then $w_{i j}=1$; conversely, $w_{i j}=0$. Eventually we have a matrix of $30 \times 30$.

The second category is the geographical distance matrix. The distance that between different provinces is an important factor that affect the spatial correlation of carbon emission and other relevant variables. Following a number of literatures, the distance matrix is set as follows:

$$
w_{d}=\frac{1}{d_{i j}^{2}}, i \neq j
$$

where $d_{i j}^{2}$ represents the distance between province $i$ and $j$. In equation (7), the distance is measured by spherical distance between the provincial capitals; if $i=j$, then $w_{d}=0$.

The third category is the gravity spatial matrix. This matrix follows the gravity model, indicating both the geographical proximity and economic relevance are important factors that affect spatial interaction and economic activities. The consideration is that, even when two provinces are adjacent, due to their different economic development level and operation mode, they may not possibly have close spatial correlation with each other; similarly, if two province have close development level and the government operation mode, however they are quite far from each other, it is still impossible for this two individuals to have close spatial correlation and linkages due to the geographical distance. Thus, it is necessary to induce the effect of both the geographical and economic factor to construct the weight matrix. As such, to fit the characteristics of spatial variation of the variables in our model better, following [37], we construct the gravity spatial weight matrix as follow:

$$
w_{g}=\frac{\left(\bar{E}_{i} \times \bar{E}_{j}\right)}{d_{i j}^{2}}, i \neq j
$$

Where $\bar{E}_{i}$ is the mean of per capital GDP of province $i$ during 2003-2016. This gravity spatial matrix suggests that provinces that have higher economic development level and closer geographical distance may have similar characteristics such as carbon emission and investment in fixed asset of finance.

All of the three spatial weight matrixes are standardized and the sum of elements of each row equals 1 . Based on the spatial 
weight matrixes, we first calculate the Moran's I value. Moran's I value is a measurement of spatial correlation:

$$
\text { Moran's } I=\frac{\sum \sum w_{i j}\left(x_{i}-\bar{x}\right)\left(x_{j}-\bar{x}\right)}{S^{2} \sum \sum w_{i j}}
$$

where $\mathrm{S}^{2}$ is the sample variance equals:

$$
S^{2}=\frac{\sum\left(x_{i}-\bar{x}\right)^{2}}{n}
$$

$x_{i}$ is the observed the value of a specific variable in province $i$; $w_{i j}$ is the spatial weight matrix. The value of Moran's I is between -1 and 1 . When the value is greater than 0 and isstatistically significant at a given level, this indicates the regions have similar characteristic basing on this specific variable. Further, Moran' I value can also be seen as the coefficient between the variable and its spatial lagged observations. If Moran's I value is close to 0, this shows similar observation values are not correlated in space. Basing on the spatial weight matrix and Moran's I equation, Table 3 shows the results of Moran's I estimation. Panel A in Table 3 displays the cross-sectional analysis of the Moran's I value of the carbon emission from 2003-2016, using the adjacent matrix, distance matrix and gravity matrix. Panel B then shows the results of global Moran's I value when applying the six independent variables in estimation. According to Panel A, the Moran's I value of the most years in our sample by using these three matrix are significantly positive, indicating that province with high carbon emissions is bound to gather a number of provinces with high carbon emission. In Panel B, this results is supported by controlling the explanatory variables. The coefficient is $0.111,0.212$ and 0.123 respectively, at $1 \%$ the statistically significant level. These results also suggest the spatial interaction and spatial correlation of carbon emission is more likely to occur among provinces that are economic related and geographical close to each other.

Table 3. Moran's I Value of Carbon Emission

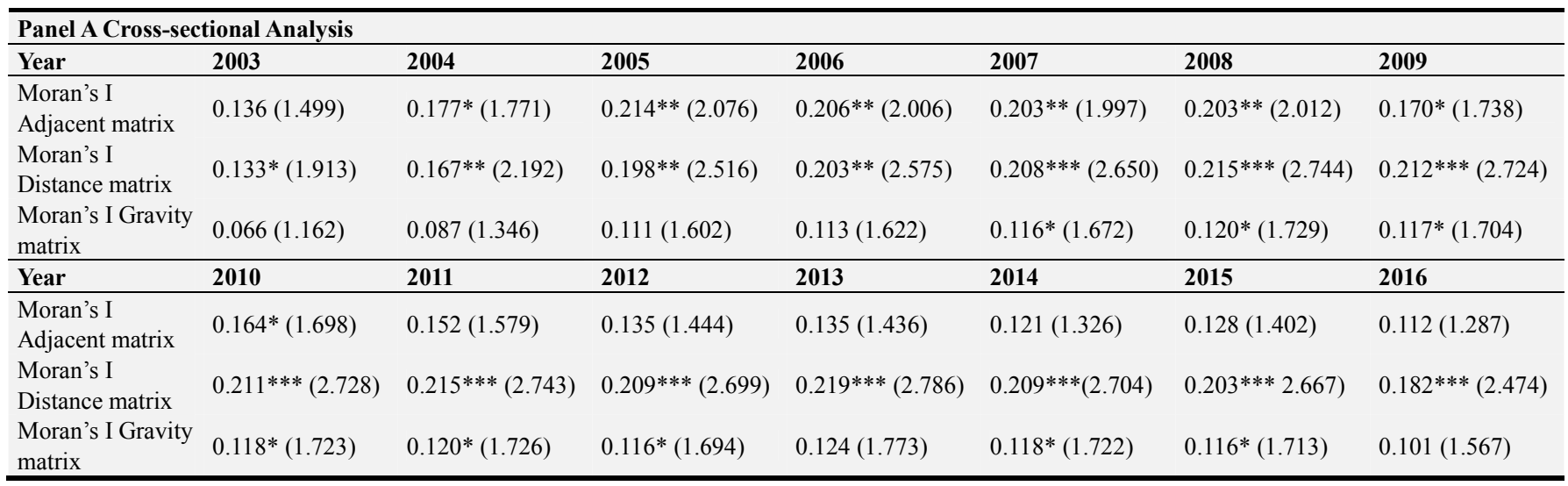

\begin{tabular}{llll}
\hline Panel B Panel Global Moran's I Value & & \\
\hline Variable & Adjacent Matrix & Distance Matrix & Gravity Matrix \\
\hline Global Moran'I (p-value) & $0.111^{* * *}(0.001)$ & $0.212 * * *(0.000)$ & $0.123 * * *(0.000)$ \\
Explanatory Variables & 6 & 6 & 6 \\
No. of Observation & 420 & 420 & 420 \\
\hline
\end{tabular}

Notes: ${ }^{* * * * * *}$, are significant level at $1 \%, 5 \%$ and $10 \% . \mathrm{Z}$ value and robust standard deviation is in parentheses.

\subsection{Identify the Spatial Econometric Model}

This paper is to study the effect of the structure of financial fixed asset investment on the provincial carbon emission, therefore it is necessary to carry out the spatial econometric test to identify the appropriate spatial econometric model and accurately estimate the mechanism and the impact. According to Elhorst [35], we construct a test that combine LM test, LR test, Wald test and Hausman test. First, the non-spatial model is estimated and the LM tests are exploited to choose the SAR or SEM model. Generally, if the LM-lag passes the test while LM-err does not, it is appropriate to choose the SAR model; otherwise the SEM model is better. Further, if both the LM-lag and LM-err pass the tests, it is necessary to compare the R-LM-lag and R-LM-err. If the R-LM-lag passes the test, then SAR model is better than SEM model, otherwise we select the
SEM model. Secondly, we check the Wald and LR tests to examine whether the SDM model can be simplified to SAR or SEM. In this test, there are two hypotheses: $\mathrm{H}_{0}^{1}: \theta=0$ andH $_{0}^{2}: \theta+$ $\beta \rho=0$. If both these two hypotheses is rejected, SDM is the best model and cannot be simplified to SAR and SEM. If the first hypothesis cannot be rejected and the LM-lag (R-LM-lag) also point to SAR, then SAR is the best model to estimate the results; if the second hypothesis cannot be rejected and LM or R-LM test points to SEM model, then SEM is the best model to estimate the spatial correlation. However, if the test results are divergent, then SDM is still the best model to estimate the data since the SDM is the general form of SAR and SEM models. Finally, Hausman tests are applied to select whether the fixed effect or random effect is more suitable to estimate the SDM. Table 4 shows the tests and their results. 
Table 4. Identify The Spatial Econometric Model.

\begin{tabular}{|c|c|c|c|c|c|c|c|}
\hline \multirow{2}{*}{ Content } & \multirow{2}{*}{ Method } & \multicolumn{2}{|c|}{ Adjacent Matrix } & \multicolumn{2}{|c|}{ Distance Matrix } & \multicolumn{2}{|c|}{ Gravity Matrix } \\
\hline & & Value & p-value & Value & p-value & Value & p-value \\
\hline \multirow{4}{*}{ SAR, SEM test } & LM-lag & 13.088 & 0.000 & 42.923 & 0.000 & 15.924 & 0.000 \\
\hline & R-LM-lag & 9.508 & 0.002 & 5.003 & 0.025 & 0.508 & 0.476 \\
\hline & LM-err & 70.051 & 0.000 & 47.902 & 0.000 & 23.328 & 0.000 \\
\hline & R-LM-err & 66.471 & 0.000 & 9.981 & 0.002 & 7.913 & 0.005 \\
\hline \multirow{3}{*}{ Simplified test of SDM } & LR-lag & 49.069 & 0.000 & 23.729 & 0.000 & 21.148 & 0.000 \\
\hline & LR-err & 49.006 & 0.000 & 22.718 & 0.000 & 20.117 & 0.001 \\
\hline & Wald-err & 50.996 & 0.000 & 23.281 & 0.000 & 20.876 & 0.000 \\
\hline Hausman & Hausman & 388.941 & 0.000 & 34.728 & 0.000 & 39.530 & 0.000 \\
\hline
\end{tabular}

According to the results from Table 4, all the LM-lag, LM-err, R-LM-lag and R-LM-err tests are statistically significant at $1 \%$ level under these three spatial weight matrixes; further, the values of Wald-lag, LR-lag, Wald-err and Wald-lag are all statistically significant at $1 \%$ level under these three spatial matrixes, which indicates that the SDM cannot be simplified to SAR or SEM. Moreover, based on the Hausman tests, fixed effect SDM is the best model to describe the data under these three spatial weight matrix. Therefore, we finally apply the SDM model with the fixed effect.

\subsection{Results with the Estimation of Spatial Econometric Model}

Applying the fixed effect SDM, we have the estimated results, which are listed in Table 5. Since in SDM, the spatial lag term of carbon emission is endogenous variable, the MLE is exploited to estimate the models to acquire the consistent parameter estimation. The results shows that the spatial auto regression coefficient $\rho$, is statistically significant at $1 \%$ level under three spatial weight matrix in most models, meaning there is an obvious spatial dependency for the provincial carbon emission under the effect of the exogenous variables that are introduced in our model. This result is also consistent with our abovementioned expectation. Moreover, the log likelihood value is included. The column (1), (3) and (5) shows the results that without control variables and column (2), (4) and (6) control the relevant variables. The coefficients of fin $_{i t}$ are stable and significantly negative under the three spatial weight matrixes, indicating that the investment in fixed asset of finance has significantly negative effect on the carbon emission. These results satisfy our expectation in the story aforementioned, reflecting that the channel of the investment in fixed asset of finance may promote the technology innovation by helping to develop the local financial environment possibly exists.

Table 5. Spatial Regression \& Effect.

\begin{tabular}{|c|c|c|c|c|c|c|}
\hline & (1) Adjacent & (2) Adjacent & (3) Distance & (4) Distance & (5) Gravity & (6) Gravity \\
\hline $\mathrm{fin}_{\text {it }}$ & $-0.306 * *(0.146)$ & $-0.339 * *(0.143)$ & $-0.358 * *(0.140)$ & $-0.329 * *(0.133)$ & $-0.398 * * *(0.141)$ & $-0.348 * *(0.140)$ \\
\hline $\mathrm{W}_{\text {fin }}$ it & $0.407 *(0.212)$ & $-0.013(0.191)$ & $0.539 * *(0.229)$ & $0.350 * *(0.166)$ & $0.680 * * *(0.191)$ & $0.348 * * *(0.135)$ \\
\hline Direct Effect & $-0.239(0.185)$ & $-0.345^{* *}(0.157)$ & $-0.268(0.447)$ & $-0.318 * *(0.135)$ & $-0.272(0.188)$ & $-0.340 * *(0.142)$ \\
\hline Indirect Effect & $0.772(1.244)$ & $-0.164(0.313)$ & $1.555(11.853)$ & $0.351 *(0.179)$ & $2.340(2.376)$ & $0.340 * *(0.136)$ \\
\hline$\rho$ & $0.760 * * *(0.084)$ & $0.269 *(0.153)$ & $0.842 * * *(0.063)$ & $0.119(0.113)$ & $0.816 * * *(0.061)$ & $0.069(0.094)$ \\
\hline Control Variables & NO & YES & $\mathrm{NO}$ & YES & NO & YES \\
\hline Log Likelihood & 97.330 & 205.465 & 127.963 & 208.418 & 127.042 & 208.101 \\
\hline
\end{tabular}

Notes: ${ }^{* * * * * *}$, are significant level at $1 \%, 5 \%$ and $10 \%$. Robust standard deviation in parentheses.

Furthermore, when the spatial spillover effect exists, the change of $f i n_{i t}$ not only affects the carbon emission of the local province, but also influences the emission of the neighboring provinces; that is, the relevant variables may cause a series of adjustment changes according to the feedback effect [31]. Generally, considering the setting of global effect in SDM, the coefficient of the explanatory variable only shows the direction and significance and cannot represent the total effect of the explanatory variable on the carbon emission. In order to obtain the total effect of financial fixed asset investment on the carbon emission, we further apply the method of LeSage and Pace [38] and estimate the direct and indirect effects of the structure of investment in financial fixed asset under the three spatial matrixes. The direct effect displays the impact of the structure of investment in financial fixed asset on local carbon emission, including the feedback effect, that means, the fin $_{i t}$ changes in one province may affect the carbon emissions of neighboring provinces and the neighboring provinces, in turn, affect the carbon emission in local region. The indirect effect then reflects the spatial effect of $\mathrm{fin}_{i t}$ on the surrounding regions' carbon emission, indicating the spillover effects. In Table 5 we report both the direct and indirect effects, the coefficient of the direct effect of the investment in financial fixed asset is significantly negative when we control the related variables, while the indirect effect of explanatory variable only significantly positive under the distance and gravity matrix, indicating that the investment in financial fixed asset reduce the carbon emission level, however possibly increase the carbon emission of the surrounding cities. Thereason behind these resultsmay be that the financial fixed asset investment in local area truly promotes the development of 
local financial environment and then, leads to a higher level of corporate innovation, finally reduce the carbon emission level. However, with the agglomeration of the financial factors, it is possible for surrounding areas lacking of sufficient allocation of financial resource since all these resource has been gathered into relatively more developed regions. Without enough financial support, surrounding regions are not able to innovate effectively and therefore, the carbon emission level are increasing conversely.

\subsection{Regional Differences Between Eastern, Middle and Western Area}

Based on the statement of National Bureau of Statistics of the People's Republic of China [39], provinces in China are divided into three main regions: eastern area, middle area and western area. First, the eastern area contains 11 provinces and are defined as the relatively developed area in China, consisting of Beijing, Tianjin, Liaoning, Shanghai, Jiangsu, Zhejiang, Fujian, Shandong, Guangdong, Guangxi, Hainan. The development level of middle area is intermediate, containing Shanxi, Inner Mongolia, Jilin, Heilongjiang, Anhui, Jiangxi, Henan, Hubei, Hunan. The western area is underdeveloped and there are 10 individuals including Chongqing, Sichuan, Guizhou, Yunnan, Tibet, Shanxi, Gansu, Ningxia, Qinghai, Xinjiang. Since the data of the Tibet is lacking seriously, our sample contains the data of the remaining 30 provinces.

Table 6. Regional Difference.

\begin{tabular}{|c|c|c|c|c|}
\hline \multicolumn{5}{|l|}{ Panel A East } \\
\hline & (1) OLS & (2) Adjacent & (3) Distance & (4) Gravity \\
\hline$f_{i n}$ & $-0.127(0.101)$ & $-0.244(0.149)$ & $-0.232(0.161)$ & $-0.265 *(0.156)$ \\
\hline Direct Effect & & $-0.229(0.152)$ & $-0.243(0.170)$ & $-0.270 *(0.162)$ \\
\hline Indirect Effect & & $0.416 * *(0.164)$ & $0.383 * * *(0.117)$ & $0.380 * *(0.155)$ \\
\hline Control Variables & YES & YES & YES & YES \\
\hline Log Likelihood & & 90.359 & 80.828 & 44.173 \\
\hline No. of Obs & 154 & 154 & 154 & 154 \\
\hline
\end{tabular}

\begin{tabular}{lllll}
\hline Panel B Middle & & & \\
\hline & (1) OLS & (2) Adjacent & (3) Distance \\
\hline fin $_{i t}$ & $0.049(0.080)$ & $-0.068(0.068)$ & $-0.050(0.068)$ & (4) Gravity \\
Direct Effect & & $-0.036(0.088)$ & $-0.033(0.072)$ & $-0.042(0.071)$ \\
Indirect Effect & & $-0.227 * *(0.108)$ & $-0.163^{* *}(0.066)$ & $-0.027(0.074)$ \\
Control Variables & YES & YES & YES & YES \\
Log Likelihood & & 160.441 & 76.681 & 75.430 \\
No. of Obs & 112 & 112 & 112 & 112 \\
\hline
\end{tabular}

\begin{tabular}{|c|c|c|c|c|}
\hline \multicolumn{5}{|l|}{ Panel C West } \\
\hline & (1) OLS & (2) Adjacent & (3) Distance & (4) Gravity \\
\hline $\mathrm{fin}_{i t}$ & $0.156 *(0.090)$ & $-0.066(0.124)$ & $0.058(0.117)$ & $0.032(0.105)$ \\
\hline Direct Effect & & $-0.117(0.141)$ & $0.062(0.122)$ & $0.036(0.113)$ \\
\hline Indirect Effect & & $-0.672(0.586)$ & $0.077(0.173)$ & $0.099(0.172)$ \\
\hline Control Variables & YES & YES & YES & YES \\
\hline Log Likelihood & & 98.615 & 89.445 & 85.774 \\
\hline No. of Obs & 154 & 154 & 154 & 154 \\
\hline
\end{tabular}

Notes: ${ }^{* * * * * *}$, are significant level at $1 \%, 5 \%$ and $10 \%$. Robust standard deviation in parentheses.

Table 6 shows the results that estimate the regional differences. From Panel A to Panel C, we use the subsample of the provinces in easternunder gravity matrix, middle and western areas under the OLS and spatial econometric estimation. We observe an interesting pattern: the effect of financial fixed asset investment is only statistically significant in eastern are aunder gravity matrix, while it is not when estimating the middle and western samples. Moreover, the indirect effect of the $f_{i n} i_{i t}$ is significantly positive in eastern area while this effect is opposite when it is in the middle area. To explain this, first we need to know that the development level of eastern area is higher than other parts of China, the agglomeration of financial factors in eastern area though promotes the development of financial market, however it may has complementary effect on the surrounding areas. More precisely, surrounding areas do not need to construct a more developed financial market since they are near a "financial center". Therefore the structure of fixed asset investment may vary among areas. The structure of fixed investment, which differs from a more financially developed area, may lead to a higher level of carbon emission. Another explanation is that the competition between the eastern provinces is much more intense, so the negative effect of competition on financial development maybe greater than the positive spillover effect of the agglomeration, among the surrounding areas. These shown by the results that the indirect effect of $f_{i n}$ is significantly positive in eastern area. However in middle area, the competition between different provinces is much weaker, a more cooperative environment drives provinces to exchange resource and then, promotes the development of each other. So, the indirect effect of in $_{i t}$ is significantly negative. The 
effect of in $_{i t}$ is not statistically significantly in western area.

\subsection{The Financial Market Channel}

In our abovementioned story, we argued that the structure of financial fixed asset investment are endogenously related with the financial development, and only through efficient financial market, the financial fixed asset investment can increase the regional innovation and then, help to reduce the carbon emission. Therefore, to examine the channel that how financial fixed asset investment affect the carbon emission through financial market is the key process to certify our story. In this part, we introduce two main methods to prove this channel. First, since our sample last 14 years, which is from 2003 to 2016, the financial crisis can be a good time node to test this channel. Due to lack of effective mechanism of financial market during the financial crisis, the channel is supposed to be not efficient when it is during the financial crisis years when compared to the other years. Panel A shows the results: column (1) and (2) display the results based on subsample when it is during 2007-2009, and when it is during the other years. We can observe that the coefficient of the explanatory variable during financial crisis is indeed not significant while compared with when it is the subsample of the other years. Moreover we apply the dummy variable cris which represents the financial crisis years to test the coefficient of the interaction between the financial fixed asset investment and financial crisis period or non-crisis period. According to column (3) to Column (6), the results are similar when using the OLS and the spatial econometric estimation. These results illustrate the negative effect of financial fixed asset investment only works when there exists an efficient financial environment.

Table 7. The Channel of Financial Market.

\begin{tabular}{|c|c|c|c|c|c|c|}
\hline \multicolumn{7}{|c|}{ Panel A Test of Financial Crisis } \\
\hline & (1) 2007-2009 & (2) other years & (3) full sample & (4) Adjacent & (5) Distance & (6) Gravity \\
\hline $\operatorname{fin}_{i t}$ & $0.046(0.117)$ & $-0.396 * * *(0.090)$ & & & & \\
\hline fin $_{i t} \times$ noncris & & & $-0.384 * * *(0.083)$ & $-0.387 * * *(0.140)$ & $-0.370^{* * *}(0.132)$ & $-0.390 * * *(0.140)$ \\
\hline fin $_{i t} \times$ cris & & & $0.111(0.194)$ & $0.113(0.205)$ & $0.111(0.155)$ & $0.123(0.151)$ \\
\hline Control Variables & YES & YES & YES & YES & YES & YES \\
\hline Log Likelihood & & & & 210.728 & 214.459 & 214.410 \\
\hline Number of Observation & 420 & 420 & 420 & 420 & 420 & 420 \\
\hline
\end{tabular}

\begin{tabular}{|c|c|c|c|c|c|c|}
\hline \multicolumn{7}{|c|}{ Panel B High Financial Development vs Low Financial Development } \\
\hline & (1) High Samples & (2) Low Samples & (3) Full samples & (4) Adjacent & (5) Distance & (6) Gravity \\
\hline $\mathrm{fin}_{i t}$ & $-0.325 * * *(0.089)$ & $-0.288 *(0.156)$ & & & & \\
\hline fin $_{i t \times}$ fin_high & & & $-0.339 * * *(0.097)$ & $-0.381 * *(0.169)$ & $-0.350 * *(0.158)$ & $-0.364 * *(0.168)$ \\
\hline fin $_{\text {it } \times \text { fin low }}$ & & & $-0.355 *(0.146)$ & $-0.275 *(0.160)$ & $-0.303 *(0.161)$ & $-0.327 * *(0.158)$ \\
\hline Control Variables & YES & YES & YES & YES & YES & YES \\
\hline Log Likelihood & & & & 206.657 & 208.753 & 208.319 \\
\hline Number of Observation & 210 & 210 & 420 & 420 & 420 & 420 \\
\hline
\end{tabular}

Notes: ${ }^{* * * * * *}$, are significant level at $1 \%, 5 \%$ and $10 \%$. Robust standard deviation in parentheses.

In Panel B, we further exploit another measure to examine this channel. Since different regions have various financial development level, according to our theory, in the higher financially developed samples, the negative effect financial fixed asset investment on the carbon emission should be more significant and also greater than the less developed area. The analysis of regional difference in 3.4 has partly provide the evidence of this channel. Based on this point, we use a simple variable to measure the financial development level, which is the proportion of the value added of financial industry in one specific area. If this region is higher financially developed, the proportion of value added of financial industry should be higher than the less developed regions. Therefore, we set the median of this ratio as the cut off to further set the dummy variable high and low: if the ratio is greater than the median value of each year, fin_high $=1$, otherwise fin_high $=0$. The setting is opposite to the dummy variable fin_low. The data of value added of financial industry is from China Statistical Yearbook for Regional Economy. We use both the subsample regression and full sample regression including interaction between financial fixed asset investment and these two dummy variables, and the spatial correlation is also taken into consideration. We can observe that the effect of investment in fixed asset of finance of high financially developed samples is greater and more statistically significant than less developed ones. Column (3) to column (6) shows similar results, indicating that the investment in fixed asset of finance indeed influence carbon emission through a good financial market.

\subsection{The Innovation Channel}

The investment in fixed asset of finance affects the carbon emission through the financial market, and since a number of literatures have emphasize the effect of financial market on regional innovation, we further test whether the financial fixed asset investment influences the carbon emission through innovation. Generally, the innovation related variable includes the R\&D investment, patent apply, patent authorized and so on. In this analysis we use the $\mathrm{R} \& \mathrm{D}$ investment $\left(R \& D \_\right.$invest $\left._{i t}\right)$ as the innovative investment and the energy efficient $\left(e e_{i t}\right)$ as the carbon emission related innovative output. The $R \& D$ investment is measures by logarithm of local R\&D investment of the industrial enterprises that above designated size, whose data is from Chinese Science and Technology Statistics Yearbook. The energy efficient, which indicates the 
technology level that relates to carbon emission, is measured as GDP amount (100 million) per 10000 ton carbon emission. We use the mediatoranalys is in the estimation with fixed effect identification strategy. The results are shown in Panel A of Table 8 .

Table 8. The Channel of R\&D Investment, Technical Output and Transfer.

\begin{tabular}{|c|c|c|c|c|c|c|c|}
\hline \multicolumn{8}{|c|}{ Panel A Channels of Financial Fixed Investment on R\&D } \\
\hline Dependent Variable & (1) $R \& D$ invest ${ }_{i t}$ & (2) lnce $_{i t}$ & (3) lnce $_{i t}$ & (4) $e e_{i t}$ & (5) lnce $_{i t}$ & (6) lnce $_{i t}$ & (7) lnce $_{\text {it }}$ \\
\hline $\operatorname{fin}_{i t}$ & $1.335 * * *(0.301)$ & & $\begin{array}{l}-0.295 * * * \\
(0.080)\end{array}$ & $0.315 * * *(0.057)$ & & $-0.013(0.058)$ & $-0.009(0.058)$ \\
\hline$R \& D$ invest ${ }_{i t}$ & & $\begin{array}{l}-0.051 * * * \\
(0.014)\end{array}$ & $\begin{array}{l}-0.037 * * * \\
(0.013)\end{array}$ & & & & $-0.004(0.010)$ \\
\hline$e e$ & & & & & $\begin{array}{l}-1.059 * * * \\
(0.110)\end{array}$ & $\begin{array}{l}-1.054 * * * \\
(0.117)\end{array}$ & $\begin{array}{l}-1.048 * * * \\
(0.120)\end{array}$ \\
\hline Sobel Test & & & $-0.050 * *(0.020)$ & & & $\begin{array}{l}-0.331 * * * \\
(0.048)\end{array}$ & \\
\hline Control Variables & YES & YES & YES & YES & YES & YES & YES \\
\hline Region Fixed Effect & YES & YES & YES & YES & YES & YES & YES \\
\hline Year Fixed Effect & YES & YES & YES & YES & YES & YES & YES \\
\hline No. of Observation & 420 & 420 & 420 & 420 & 420 & 420 & 420 \\
\hline
\end{tabular}

\begin{tabular}{|c|c|c|c|c|}
\hline \multicolumn{5}{|c|}{ Panel B Effect of Financial Fixed Investment on Technical transformation } \\
\hline Dependent Variable & (8) $R \& D$ D_invest $t_{i t}$ & (9) $e e_{i t}$ & (10)e $e e_{i t}$ & (11) $e e_{i t}$ \\
\hline $\operatorname{fin}_{i t-1}$ & $1.335 * * *(0.301)$ & & $0.272 * * *(0.058)$ & \\
\hline$R \& D_{\text {invest }}{ }_{\text {it }}$ & & $0.044 * * *(0.007)$ & $0.032 * * *(0.007)$ & $0.021 * *(0.009)$ \\
\hline $\operatorname{fin}_{i t-1} \times R \& D$ & & & & $0.069 * * *(0.016)$ \\
\hline Control Variables & YES & YES & YES & YES \\
\hline Region Fixed Effect & YES & YES & YES & YES \\
\hline Year Fixed Effect & YES & YES & YES & YES \\
\hline No. of Observation & 360 & 390 & 360 & 360 \\
\hline
\end{tabular}

Notes: ${ }^{* * * * *}$, are significant level at $1 \%, 5 \%$ and $10 \%$. Robust standard deviation in parentheses.

Column (1) to (3) display the results of the mediator test of the R\&D investment. Column (1) shows that when we control the relevant variables, the investment in fixed asset of finance have significantly positive relationship with the R\&D investment; moreover, column (2) indicates that R\&D investment indeed reduce the local carbon emission. When combining the financial fixed asset investment and R\&D investment, the effect of investment in financial fixed asset first become less significant and the effect is weaker when compared to former estimation, which indicates that the R\&D investment in one of the mediators between financial fixed asset investment and carbon emission. According to column (4) to (6), the results are similar, showing that the energy efficiency is also an effective mediator. Further, column (7) displays the result when we introduce all the variables, the effect of investment in fixed asset of finance and R\&D investment become not significant while only the energy efficiency is significantly negative at $1 \%$. This result illustrates that the innovation output is the final factor that affect the carbon emission. Moreover, both the Sobel tests column (3) and column (6) further clarify the mediating effect. In sum, by exploiting the mediator analysis, the channel of innovation is examined to exist.

We set an extension analysis of the impact of financial fixed asset investment when considering the technology transfer. The story tested is that, when the investment in fixed asset of finance occurred two years ago and this should increase the R\&D investment one year ago, the last year is also the time for the technology transfer. In this story, since the investment in fixed asset of finance may also influence the technology transfer through financial market, in Panel B of Table 8, we examine this potential mechanism. According to column (8) to (10), the story aforementioned exists. In order to further test the impact of explanatory variable on the technology transfer, we set an interaction that combing the financial fixed asset investment which is lagged by one orders and the R\&D investment. The coefficient of this interaction is significantly positive at $5 \%$ level, indicating that technology transfer is indeed promoted by the financial fixed asset investment as well.

\subsection{Robustness Check}

Robustness check is applied in this paper and the results are shown in Table 9. In Panel A and Panel B, we follows Tong and $\mathrm{Wu}$ [36] and set two variables represent the relative structure of investment in fixed asset of finance. First, we apply the relative ratio between financial fixed asset investment and the investment in fixed asset of transportation as the explanatory variable and the results are shown in Panel A. Moreover in Panel B, the key explanatory variable is measured by the ratio of the investment in fixed asset of finance divided by the fixed asset investment of transportation plus the fixed asset investment in public infrastructure and real 
estate, due to the importance of the additional two kinds of fixed asset investment. Data of this two variables derives from China Statistical Yearbook for Regional Economy. In both Panel A and Panel B, the effect of these two alternative variables is still stable and statistically significant, indicating a similar effect to previous analysis.

According to Agénor\& Moreno-Dodson [40], the stock of fixed asset is the key factor that influence the economic growth. Therefore, in Panel C, we further calculate the stock of investment in fixed asset of finance by years following Zhang and Song [41]. In Panel C, results indicate that the effect of the stock of investment in financial fixed asset is similar.

In our story, the consideration is that the impact of investment in fixed asset of finance exists the lag effect, therefore it is also necessary to identify whether explanatory variable lagged one order is appropriate for estimation. Panel
D lists the results of the explanatory variable lagged from one order to three order. It is obvious that the effect of the variable lagged for one order is most significant and the effect is also greater than others, which indicates the explanatory variable we apply in previous analysis is appropriate and the relevant results are robust as well.

Panel E lists the results of using other relevant spatial econometric model, including the SAR and SEM. Moreover, the dynamic spatial model contains space-time lagged explanatory variable is exploited as well and all the results are similar to previous estimation.

In Panel F and Panel G, we set the logarithm of the number of patent application and patent authorization as alternative variables of technical output, to recheck the channels in 3.6. According to the estimation, the results are still similar to the previous analysis when controlling relevant variables, year fixed effect and regional fixed effect.

Table 9. Robustness Check.

\begin{tabular}{|c|c|c|c|c|}
\hline \multicolumn{5}{|c|}{ Panel A Relative Investment Structure Changes-Transportation } \\
\hline & OLS & Adjacent & Distance & Gravity \\
\hline fin_t $t_{i t}$ & $-0.022 * * *(0.006)$ & $-0.020 * *(0.009)$ & $-0.019 * *(0.009)$ & $-0.020 * *(0.010)$ \\
\hline Control Variables & YES & YES & YES & YES \\
\hline Log Likelihood & & 199.311 & 203.792 & 202.309 \\
\hline No. of Observation & 420 & 420 & 420 & 420 \\
\hline & OLS & Adjacent & Distance & Gravity \\
\hline fin_tp $p_{i t}$ & $-0.001 * * *(0.000)$ & $-0.001(0.001)$ & $-0.001(0.001)$ & $-0.001(0.001)$ \\
\hline Control Variables & YES & YES & YES & YES \\
\hline Log Likelihood & & 201.300 & 201.186 & 200.082 \\
\hline No. of Observation & 420 & 420 & 420 & 420 \\
\hline
\end{tabular}

\begin{tabular}{lllll}
\hline Panel C Stock Measurement & & & \\
\hline & OLS & Adjacent & Distance \\
\hline fin_stock $k_{\text {it }}$ & $-0.813^{* * *}(0.178)$ & $-1.056^{* *}(0.527)$ & $-1.066^{* *}(0.487)$ & Gravity \\
Control Variables & YES & YES & YES & $-1.066^{* *}(0.469)$ \\
Log Likelihood & & 218.950 & 219.416 & YES \\
No. of Observation & 420 & 420 & 420 & 219.514 \\
\hline
\end{tabular}

\begin{tabular}{|c|c|c|c|c|}
\hline \multicolumn{5}{|c|}{ Panel D Identify The Best Lag Order } \\
\hline & OLS & Adjacent & Distance & Gravity \\
\hline $\mathrm{fin}_{i t}$ & $-0.225 * *(0.090)$ & $-0.242 * *(0.108)$ & $-0.213 * *(0.100)$ & $-0.223 * *(0.102)$ \\
\hline $\operatorname{fin}_{i t-1}$ & $-0.182 * *(0.089)$ & $-0.178 * *(0.082)$ & $-0.207 * *(0.082)$ & $-0.215^{* * *}(0.082)$ \\
\hline$f_{i n} n_{i t-2}$ & $-0.141 *(0.084)$ & $-0.137(0.115)$ & $-0.188(0.124)$ & $-0.182(0.127)$ \\
\hline Control Variables & YES & YES & YES & YES \\
\hline Log Likelihood & & 213.023 & 217.792 & 218.000 \\
\hline
\end{tabular}

\begin{tabular}{llll}
\hline \multicolumn{2}{l}{ Panel E Other Spatial Estimation Models } & & \\
\hline & Adjacent & Distance & Gravity \\
\hline SAR-fin $n_{i t}$ & $-0.267 *(0.151)$ & $-0.269 *(0.149)$ & $-0.268^{*}(0.151)$ \\
Log Likelihood & 192.175 & 193.983 & 191.745 \\
SEM-fin ${ }_{i t}$ & $-0.268^{*}(0.150)$ & $-0.290^{*}(0.161)$ & $-0.289^{*}(0.165)$ \\
Log Likelihood & 189.688 & 185.889 & 184.852 \\
Dynamic-fin $n_{i t}$ & $-0.259^{*}(0.138)$ & $-0.262 *(0.135)$ & $-0.257^{*}(0.138)$ \\
Log Likelihood & 204.613 & 208.626 & 205.196 \\
No. of Observation & 420 & 420 & 420 \\
\hline
\end{tabular}




\begin{tabular}{|c|c|c|c|}
\hline \multicolumn{4}{|c|}{ Panel F Patent As Proxy of Technology To Check Channels } \\
\hline Dependent Variable & patent_apply ${ }_{i t}$ & lnce $_{i t}$ & lnce $_{i t}$ \\
\hline$f i n_{i t}$ & $1.556^{* * *}(0.325)$ & & $-0.296 * * *(0.078)$ \\
\hline patent_apply ${ }_{i t}$ & & $-0.044 * * *(0.010)$ & $-0.031 * * *(0.009)$ \\
\hline No. of Observation & 420 & 420 & 420 \\
\hline Dependent Variable & patent_authorized & lnce $_{i t}$ & lnce $_{i t}$ \\
\hline $\operatorname{fin}_{i t}$ & $1.391 * * *(0.298)$ & & $-0.288 * * *(0.078)$ \\
\hline patent_authorized $_{i t}$ & & $-0.053 * * *(0.010)$ & $-0.041 * * *(0.010)$ \\
\hline No. of Observation & 420 & 420 & 420 \\
\hline \multicolumn{4}{|c|}{ Panel G Check Effect of Fixed Investment of Finance on Transaction } \\
\hline Dependent Variable & patent_apply ${ }_{i t}$ & patent_apply ${ }_{i t}$ & patent_apply ${ }_{i t}$ \\
\hline$f i n_{i t-1}$ & & $0.160(0.129)$ & \\
\hline$R \& D_{\text {investment }}{ }_{i t}$ & $1.048 * * *(0.022)$ & $1.034 * * *(0.026)$ & $1.034 * * *(0.025)$ \\
\hline$f i n_{i t-1} \times R \& D$ & & & $0.026 *(0.014)$ \\
\hline No. of Observation & 420 & 420 & 420 \\
\hline Dependent Variable & patent_authorized $_{i t}$ & patent_authorized $_{i t}$ & patent_authorized $_{\text {it }}$ \\
\hline$f i n_{i t-1}$ & & $0.248^{*}(0.147)$ & \\
\hline$R \& D$ investment ${ }_{i t}$ & $0.986^{* * *}(0.025)$ & $0.973 * * *(0.030)$ & $0.971 * * *(0.029)$ \\
\hline$f i n_{i t-1} \times R \& D$ & & & $0.045^{* * *}(0.017)$ \\
\hline No. of Observation & 420 & 420 & 420 \\
\hline Control Variables & & YES & \\
\hline Region Fixed Effect & & YES & \\
\hline Year Fixed Effect & & YES & \\
\hline
\end{tabular}

Notes: ${ }^{* * * * * *}$, are significant level at $1 \%, 5 \%$ and $10 \%$. Robust standard deviation in parentheses.

\section{Conclusion}

This paper investigates the way of financial fixed asset investment affecting carbon emission. Through financial market, fixed asset investment of finance can promote technical innovation and reduces carbon emission. Utilizing the fixed effect identification strategy and spatial econometric model, the effect and the channels between these two factors are verified. Firstly, it is found that fixed asset investment of finance has significantly negative relationship with the regional carbon emission. By controlling relevant variables and utilizing the spatial econometric analysis, the results are robust. Secondly, this effect only exists in the eastern areas of China; by analyzing the case of financial crisis and the samples with heterogeneous financial development level, it is further found that financial market is the channel between financial fixed asset investment and carbon emission. Thirdly, it is also found that technological innovation is another channel from financial fixed asset investment to carbon emission, that is, by increasing technological innovation level, fixed asset investment of finance can reduce carbon emission and further increases technology transfer efficiency. With alternative intermediate variables, the results are robust as well. Overall, our results indicate that financial fixed asset investment is an important determinant that influences carbon emission. This paper contributes to the study on the relationship between investment structure and carbon emission, and provides new insight to the channels between these two factors.

\section{References}

[1] Zhang, X. P., Cheng, X. M., 2009. Energy consumption, carbon emissions, and economic growth in China. Ecological Economics, 68 (10), 2706-2712.

[2] Zhang, Y. J., 2011. The impact of financial development on carbon emissions: An empirical analysis in China. Energy Policy, 39 (4), 2197-2203.

[3] Wang, S. S., Zhou, D. Q., Zhou, P. et al., 2011. $\mathrm{CO}_{2}$ emissions, energy consumption and economic growth in China: A panel data analysis. Energy Policy, 39 (9), 4870-4875.

[4] Goodall, C., Goodall, C., 2007. How to live a low-carbon life: the individual's guide to stopping climate change. Earthscan, UK.

[5] Spence, C., 2014. Global warming: Personal solutions for a healthy planet. St. Martin's Press, New York.

[6] Dietz, T., Gardner, G. T., Gilligan, J. et al., 2009. Household actions can provide a behavioral wedge to rapidly reduce US carbon emissions. Proceedings of the National Academy of Sciences of the United States of America, 106 (44), 18452-18456.

[7] Jones, C. M., Kammen, D. M., 2011. Quantifying carbon footprint reduction opportunities for U.S. households and communities. Environmental Science \& Technology, 45 (9), 4088-4495.

[8] Druckman, A., Chitnis, M., Sorrell, S. et al., 2011. Missing carbon reductions? Exploring rebound and backfire effects in UK households. Energy Policy, 39 (6), 3572-3581. 
[9] Price L, Worrell E. International industrial sector energy efficiency policies [J]. Office of Scientific \& Technical Information Technical Reports, 2000.

[10] Cai, W., Wang, C., Wang, K. et al., 2007. Scenario analysis on $\mathrm{CO}_{2}$ emissions reduction potential in China's electricity sector. Energy Policy, 35 (12): 6445-6456.

[11] Atkins, M. J., Morrison, A. S., Walmsley, M. R. W., 2010. Carbon emissions pinch analysis (CEPA) for emissions reduction in the New Zealand electricity sector. Applied Energy, 87 (3): 982-987.

[12] Liu, Z., Guan, D., Wei, W., et al., 2015. Reduced carbon emission estimates from fossil fuel combustion and cement production in China. Nature, 524 (7565), 335.

[13] Wang, K., Wang, C., Lu, X., et al., 2007. Scenario analysis on $\mathrm{CO}_{2}$ emissions reduction potential in China's iron and steel industry. Energy Policy, 35 (4), 2320-2335.

[14] Hasanbeigi, A., Morrow, W., Sathaye, J., et al., 2013. A bottom-up model to estimate the energy efficiency improvement and $\mathrm{CO}_{2}$ emission reduction potentials in the Chinese iron and steel industry. Energy, 50, 315-325.

[15] Li, Y., Zhu, L., 2014. Cost of energy saving and $\mathrm{CO}_{2}$ emissions reduction in China's iron and steel sector. Applied Energy, 130, 603-616.

[16] Holtz-Eakin, D., Selden, T. M., 1995. Stoking the fires? $\mathrm{CO}_{2}$ emissions and economic growth. Journal of public economics, $57(1), 85-101$.

[17] Halicioglu, F., 2009. An econometric study of $\mathrm{CO}_{2}$ emissions, energy consumption, income and foreign trade in Turkey. Energy Policy, 37 (3), 1156-1164.

[18] O'neill, B. C., Dalton, M., Fuchs, R. et al., 2010. Global demographic trends and future carbon emissions. Proceedings of the National Academy of Sciences, 107 (41), 17521-17526.

[19] Wang, S., Fang, C., Guan, X., et al., 2014. Urbanization, energy consumption, and carbon dioxide emissions in China: a panel data analysis of China's provinces. Applied Energy, 136, 738-749.

[20] Pao, H. T., Tsai, C. M., 2011. Multivariate Granger causality between $\mathrm{CO}_{2}$ emissions, energy consumption, FDI (foreign direct investment) and GDP (gross domestic product): evidence from a panel of BRIC (Brazil, Russian Federation, India, and China) countries. Energy, 36 (1), 685-693.

[21] Lau, L. S., Choong, C. K., Eng, Y. K., 2014. Investigation of the environmental Kuznets curve for carbon emissions in Malaysia: do foreign direct investment and trade matter. Energy Policy, 68, 490-497.

[22] Ozturk, I., Acaravci, A., 2013. The long-run and causal analysis of energy, growth, openness and financial development on carbon emissions in Turkey. Energy Economics, 36, 262-267.

[23] Frankel, J. A., Romer, D. H., 1999. Does trade cause growth. American Economic Review, 89 (3), 379-399.

[24] Dasgupta, S., Laplante, B., Mamingi, N., 2001. Pollution and capital markets in developing countries. Journal of Environmental Economics and management, 42 (3), 310-335.
[25] Jalil, A., Feridun, M., 2011. The impact of growth, energy and financial development on the environment in China: a cointegration analysis. Energy Economics, 33 (2), 284-291.

[26] Shahbaz, M., Hye, Q. M. A., 2013. Tiwari A K, et al. Economic growth, energy consumption, financial development, international trade and $\mathrm{CO}_{2}$ emissions in Indonesia. Renewable and Sustainable Energy Reviews, 25, 109-121.

[27] Shahbaz, M., Solarin, S. A., Mahmood, H., et al., 2013. Does financial development reduce $\mathrm{CO}_{2}$ emissions in Malaysian economy? A time series analysis. Economic Modelling, 35, $145-152$.

[28] Boutabba, M. A., 2014. The impact of financial development, income, energy and trade on carbon emissions: Evidence from the Indian economy. Economic Modelling, 40, 33-41.

[29] Dietz, T., Rosa, E. A., 1994, Rethinking the environmental impacts of population, affluence and technology. Hum. Ecol. Rev. 1 (2), 277-300.

[30] Hsu, P. H., Tian, X., Xu, Y., 2014. Financial development and innovation: cross-country evidence. Journal of Financial Economics. 112, 116-135.

[31] Han, F., Xie, R., Lu, Y., Fang, J., Liu, Y., 2018, The effects of urban agglomeration economies on carbon emissions: evidence from Chinese cities. Journal of Cleaner Production. 172, 1096-1110.

[32] Shahbaz, M., Nasreen, S., Ozturk, L., 2016. FDI, growth and $\mathrm{CO}_{2}$ emission relationship: evidence from high, middle and low income countries. B. Energy Economics. 4 (1), 54-69.

[33] Ang, J. B., 2009. $\mathrm{CO}_{2}$ emission, research and technology transfer in China Ecology Economics. 68, 2658-2665.

[34] Zhang, Hua, 2016. Strategic interaction of regional environmental regulation-An explanation on the universality of incomplete enforcement of environmental regulation. China Industry Economics. 7, 74-90 (In Chinese).

[35] Vega, S. H., Elhorst, J. P., 2015. The Slx model. Journal of Regional Science. 55 (3), 339-363.

[36] Tong, J., Wu K. P., 2016. Infrastructure investment structure changes in the process of economic development. Journal of Quantitative Technology and Economics. 12, 61-77 (In Chinese).

[37] Hou, S. X., Zhang, Z. Y., Zhou, J. X., 2014. A study on the growth effect and affecting path of China's economic structure. Journal of World Economics. 5, 88-111 (In Chinese).

[38] LeSage, J., Pace, R. K. 2009. Introduction to spatial econometrics. CRC Press, Taylor \& Francis Group, New York.

[39] National Bureau of Statistics of the People's Republic of China, 2017. China Statistical Yearbook, China Statistical Press, Beijing.

[40] Agénor, P. R., Moreno-Dodson, B., 2006. Public infrastructure and growth: new channels and policy implications. Policy Research Working Paper, No. 4064.

[41] Zhang, G., Song, R., 2013. Transportation impact on manufacturing industry inputs in china. Economic Research Journal. 7, 63-75 (In Chinese). 